\title{
Engineering of long length CsI:TI scintillators for high energy physics
}

\author{
D.I.Zosim, A.V.Gektin \\ Institute for Scintillation Materials, STC "Institute for Single Crystals", \\ National Academy of Sciences of Ukraine, 60 Lenin Ave., 61001 Kharkov, \\ Ukraine
}

Received November 28, 2014

\begin{abstract}
It is shown that engineering of long length Csl:TI scintillators for medium and high energy physics projects significantly depends of the primary performance of scintillation single crystal. In particular statistical study on several hundred samples for different project justify significant role of the TI concentration. TI concentration gradient along the bar and final finishing (stability of surface roughness for the light collection tuning) in the technology optimization for scintillator production. It is necessary to note, that any of these parameters are not taken into account in the Monte Carlo simulation (Geant 4) that usually use as the start point for the scintillator optimization.
\end{abstract}

Keywords: scintillators, HEP, Csl:TI crystals, light collection, activator concentration

Показано, что проектирование длинномерных сцинтилляторов Csl:TI для проектов по физике высоких энергий для диапазона средних и высоких энергий в значительной степени зависит от характеристик сцинтилляционного монокристалла. В частности, изучение статистических данных нескольких сотен образцов показывает на существенную роль в оптимизации технологии производства сцинтилляторов концентрации TI, градиента концентрации ТІ вдоль бруска и финишной обработки (стабильность шероховатости поверхности, применяемой при тюнинге сбора света). Надо отметить, что каждый из этих параметров не учитывается в Монте-Карло моделировании (Geant4), которое, как правило, используют в качестве отправной точки при оптимизации параметров сцинтилляторов.

Інженерія сцинтиляторів CsI:TI великої довжини для фізики високих енергій. Д.І.Зосим, О.В.Гектін.

Показано, що проектування довгомірних сцинтиляторів Csl:TI для проектів з фізики високих енергій для діапазону середніх і високих енергій в значній мірі залежить від характеристик сцинтиляційного монокристала. Зокрема, вивчення статистичних даних декількох сотень зразків вказу на істотну роль в оптимізації технології виробництва сцинтиляторів концентрації TI, градієнту концентрації TI уздовж бруска і фінішної обробки (стабільність шорсткості поверхні, що застосовується при тюнінгу збору світла). Слід відзначити, що кожен з цих параметрів не враховується в Монте-Карло моделюванні (Geant4), яке, як правило, використовують в якості відправної точки при оптимізації параметрів сцинтилятора.

\section{Introduction}

Last decades CsI pure and TI doped crystals dominated in medium and high energy physics (HEP) experiments due to ability of their mass production as bulky long length bars [1]. Such projects as BELLE [2], BaBar [3], FAZIA [4], GLAST [5] had very similar claim for the light output uniformity along the bar (i.e the minimal deviation of the signal $\Delta_{L}$ from average) with the store of scintillation efficiency (like the light output 
$-L_{Y}$ and energy resolution $-R$ ). The new project - CALIFA [6] has to has even better uniformity then previous one and demonstrate the progress in the detector assembly performance.

Usually technology of uniformity access is based on preliminary simulation (Monte Carlo, like Geant4 [7,8] or conventional estimation [9]) that has to demonstrate the surface roughness which will lead to the light output uniformity [10-12]. Later performance was reflected the state of the art with crystal finishing, stability of the surface conditions and reflector. At the same time simulations and experimental practice always based on the assumption that the crystal physical and optical parameters are always the same and have not act to the process of detector development.

This work is directed to analysis of statistical data and deviation of long scintillator performance from average due to the influence of host crystal parameters to the scintillation uniformity.

\section{Experimental}

The main data base cover few thousands CsI(TI) samples for HEP projects [3] and [5]. Reference samples were prepared from the same quality raw material at the same technology [13]. All samples were cut and finished by the same technology too.

Absorption spectra and proper coefficient were measured at $10 \times 25 \times 45 \mathrm{~cm}$ samples (10 $\mathrm{cm}$ is the absorption length). Nevertheless $\mathrm{T} \mid$ concentration in all samples was inside the plato $\left(L=f\left(C_{\mathrm{Tl}}\right)[14]\right)$ of the scintillation yield vs. activator concentration this value was measured by an optical method as well. All samples were selected to two groups: with the uniform $\mathrm{Tl}$ concentration along the bar and with non uniform distribution. Intrinsic stress level was tested by optical polarization technique (PKS-250 [15]).

The light output and energy resolution were measured at reflector (BHA film [16]) wrapped crystals with Hamamatsu R1306 PMT on the MCA Sugan [17]. There were three typical gamma sources with energies $511,661.5$ and $1275 \mathrm{keV}$. An optical pad from PMT and samples was used. The $L$ value was measured with non collimated source removed from the crystal at the distance that was equal to the crystal length. The data spread from point to point of irradiation was estimated as

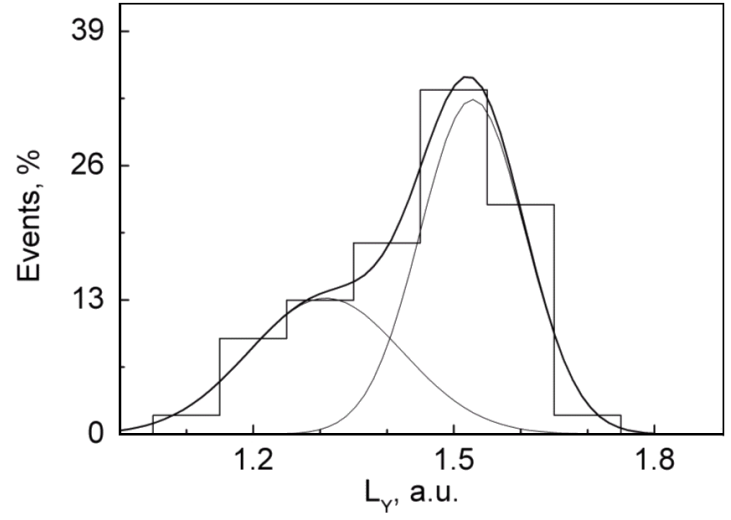

Fig. 1. Light output distribution of $1.0 \times 4.5 \times 22 \mathrm{~cm}^{3} \mathrm{Csl}(\mathrm{TI})$ bars.

$$
\begin{gathered}
\Delta_{L}=\left(L_{s, \max }-L_{s, \min }\right) / L_{a v e} \\
L_{\text {ave }}=N^{-1} \sum_{s=1} L_{S}
\end{gathered}
$$

The same $1^{\prime \prime} \times 1^{\prime \prime}$ size Csl(TI) detector was used as the reference crystal for all measurements. Spectrometry line allows sustain accuracy of $L$ measurements not wore than $0.285 \%$.

For the group with different $h / d$ rate (length $(h)$ to cross section $(d)$ size) and uniform $\mathrm{Tl}$ distribution the percentage $(p)$ (where $p=m / M ; m$ is amount of samples with $\delta L_{Y}=0, M$ is the total amount of samples) was estimated.

Refraction index ( $n$ ) was evaluated by the optical microscope equipped with the indicator Logic TM Basic (Model BG3110-3 (USA) [18]). The accuracy of the test for different optical glasses was not exceed $\sim 10^{-3}$. So, this accuracy has to be typical for our tests of $n_{\text {Csl:Tl}}$. Each data is the average result for at least 10 samples with the same $\mathrm{Tl}$ concentration in samples. The data spread at the range $10 \%$ include the difference of non controllable harmful impurities (like $\mathrm{Na}^{+}$, for example) and errors in $\mathrm{Tl}$ concentration measurements.

\section{Results}

As the typical (for different shaped samples) the $1.0 \times 4.5 \times 22 \mathrm{~cm}^{3} \mathrm{CsI}(\mathrm{TI})$ bars $(h / d=4.77)$, were selected. The proper light output distribution of these crystals is shown at Fig. 1. It is necessary to note that it looks like two peaks histogram, nevertheless in accordance with general simulation it has to be one Gauss distribution peak. 


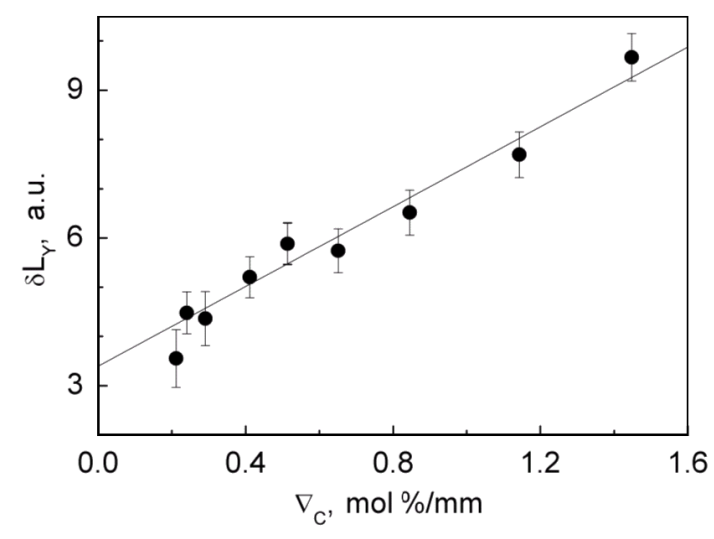

Fig. 2. Light output difference measured at opposite bar entrances as a function of the $\mathrm{TI}$ gradient.

Fig. 1 demonstrates that situation in large batches of detectors is not simple and we can propose that some third factors (except surface finishing) can deteriorate uniformity through formally similar crystals. First of all it is necessary to check the role of $\mathrm{Tl}$ concentration in Csl bars. It relates to even continuous growth technique [12] that allows minimizing the $\mathrm{Tl}$ non uniformity in the ingot comparing conventional Bridgman technique [19]. The measurements were completed with PMT matched to opposite sides of the Csl(TI) long bars with simultaneous control of $\mathrm{Tl}$ content along the bar.

Fig. 2 demonstrates the different between $L_{Y}$, that were measured at different $\mathrm{TI}$ concentration gradient $\left(\nabla_{\mathrm{C}}=\Delta_{\mathrm{Tl}} / \Delta x\right)$. It has to be noted that even gradient free samples possess with some $\delta L_{Y}$.

This phenomenon reflects activator non uniformity and depends on the $h / d$ rate. This dependence is shown at Fig. 3. The frequency of deviation from $\delta L_{Y}=0$ is rise up with increase of $h / d$ rate. (Note these measurements were made for the crystals) with the uniform distribution of $\mathrm{Tl}$ ions along the crystals).

These data demonstrate some influence of small $\mathrm{Tl}$ ions non uniformity (in the range of the light output yield) on the light output uniformity. It can be supposed that even small changes of activator content can change crystal properties and later scintillation uniformity. The refraction index was chosen as non direct criteria of crystal internal structure (properties) change. This change (dependence of refraction index decrease with $\mathrm{Tl}$ concentration growth in Csl(Tl) crystal) is visible from Fig. 4. This

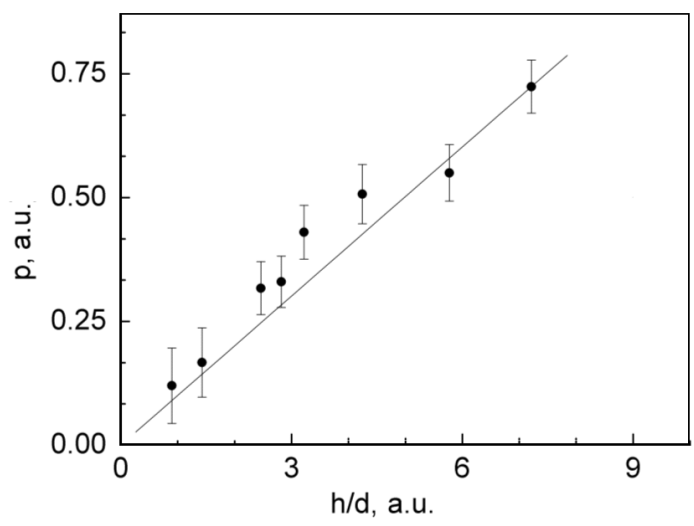

Fig. 3. Dependence of value $\delta L_{Y}=0$ on the $h / d$ rate for crystals with $C_{\mathrm{TI}}=$ const.

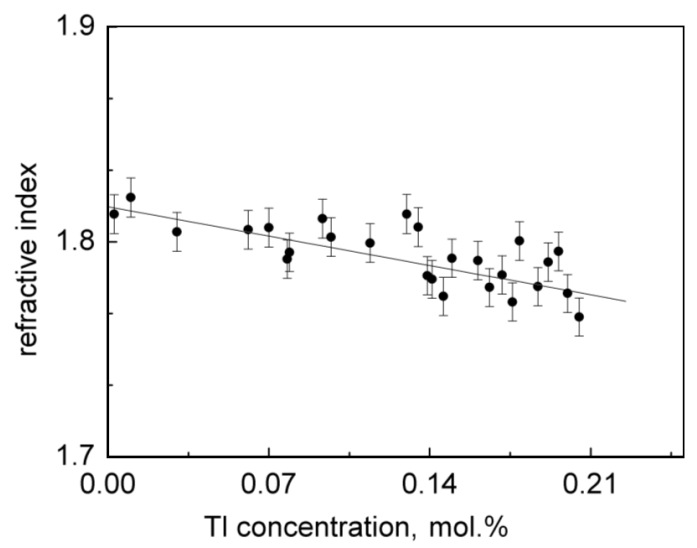

Fig. 4. Correlation between refraction index $(n)$ and $\mathrm{TI}$ concentration increase in $\mathrm{CsI}(\mathrm{TI})$ crystals.

trend is out from the spread and accuracy of the $n$ measurement.

\section{Discussion and conclusion}

Light output distribution of CsI(TI) bars (Fig. 1) reflects complex influence of minimal deviation of crystal parameters on the probability of best crystal performance for the HEP detector application. The probability to reach an optimal result does not exceed 0.47 for the light output and even less $(0.151)$ for energy resolution.

It means that in major cases the handle tuning of the surface reflectivity needs to compensate such deviations. It is necessary to select (except $\mathrm{Tl}$ concentration) yet at least two aspects that relates to the crystal structure itself. These are internal stress relaxation that can change the surface conditions and optical absorption at the emission wavelength. The first argument can be removed from analysis if a crystal sustains at stress relaxation condition during few weeks till the full surface relief. The second 
parameter influence rise up with the bar length increase, when optical losses stay significant. The spread of absorption coefficient usually does not exceed for CsI (TI) crystals $0.05 \mathrm{~cm}^{-1}$.

Refraction index selection as the criterion of the crystal deviation for an optimal (see Fig. 2, 4) has an integrated character. It includes not only $\mathrm{Tl}$ content modifications but minimal changes of lattice parameter (Vegard's rule) and later changes of internal stresses. The data obtained demonstrate that accumulation of several "influence" factor can play an important role with $h / d$ rate increase and it can be the reason for the second peak (see Fig. 1) appearance.

Finally it is necessary to note, that conventional modeling software $[7,8]$ do not include in the algorithm any of discussed above parameters or these parameters deviation form the average. It is shown that their role is not negligible and claim to be taken into account during detector design and engineering. This is why the state-ofthe-art with crystal finishing is still the key element of the long length HEP detector production.

\section{References}

1. P.Schotanus et al., IEEE Trans. Nucl. Scie., 37, 177 (1990).

2. Y.Ohshima et al., Instr. Meth. Phys. Res. . A, 380, 517 (1996).

3. Aubert et al., Nucl. Instr.Meth. Phys. A, 479, 1 (2002).

4. R.Bougault et al., The Eur. Phys. J. A Hadrons and Nuclei, 50, 2 (2014).
5. N.Gehrels, P.Michelson, Astroparticle Physics, 11, 277 (1999).

6. FAIR/NUSTAR/R3B/TDR CALIFA. Technical Report for the Design, Construction and Commissioning of The CALIFA Barrel: The R3B CALorimeter for In Flight detection of Rays and High Energy Charged Particles, 29 November (2011).

7. M.Janecek, W.W.Moses, Nucl. Scie.IEEE Trans. Nuclear Scie., 57, 964 (2010).

8. S.Agostinelli, J.Allison, K.Amako et al., $\mathrm{Nu}$ clear Instruments and Methods in Physics Research Section A, 506, 250 (2003).

9. M.E.Globus, B.V.Grinyov, Inorganic Scintillators. New and Conventional Materials, Akta, Kharkov (2000) [in Russian].

10. A.Wagner, W.P.Tan, B.Davin et al., Nucl. Instrum. Metho. Phys. A, 456, 290 (2001).

11. M.-J.van Goethema, M.S.Wallacea, B.E.Nett et al., Nuclear Instruments and Methods in Physics Research Section A, 526, 455 (2004).

12. H.'Alvarez-Pol, V.Avdeichikov, M.Bendel et al., GSI SCIENTIFIC REPORT 2010. PHNNUSTAR-NR-23, 185 (2010).

13. V.I.Goriletsky, B.V.Grinyov, B.G.Zaslavsky et al., Crystal Growth. Alkali Metal Halides, Akta, Kharkov (2002) [in Russian].

14. L.N.Trefilova, A.M.Kudin, L.V.Kovaleva et al., Nucl. Instrum. Meth. Phys. A 486, 474 (2002).

15. R.N.Kochurova, Based on Practical Petrography, L.: Publishing House of Leningrad University (1977) [in Russian].

16. http://www.egotex.com/membrane.htm

17. http://www.sugan.com.ua

18. http://www.dialindicator.com/electronic_logi c_basic.php

19. M.Margulies, P.Witomski, T.Duffar, J. Cryst. Growth, 266, 175 (2004). 